Pacific Journal of Mathematics

IRREDUCIBLE LENGTHS OF TRIVECTORS OF RANK SEVEN 


\section{IRREDUCIBLE LENGTHS OF TRIVECTORS OF RANK SEVEN AND EIGHT}

\section{R. WESTWICK}

We determine the irreducible length of complex trivectors of rank less than or equal to eight. The irreducible length is invariant under the action induced by the general linear group on the underlying complex vector space. A classification under this action is available where representatives are explicitly given for each equivalence class and it is the lengths of these representatives which are determined.

In their paper [1], Busemann and Glassco consider the problem of determining the maximal irreducible length (called length from now on) $N(F, n, r)$ of $r$-vectors in $\Lambda^{r} U$ where $U$ is an $n$-dimensional vector space over the field $F$. The length of an $r$-vector is the number of decomposable summands (blades in J. Schouten's book [5] and paper [6]) in a shortest possible representation of that $r$-vector. In [1] Busemann and Glassco state that "The values $N(C, 7,3)=5$, $N(C, 8,3)=7$, and $N(C, 9,3)=10$ have been claimed but questioned, see Schouten [3, p. 27] and [1]." The purpose of this paper is to show that $N(C, 8,3)=5$ (and not 7 as claimed) by determining the lengths of each of the representatives of the Gurevich classification in [2]. For sake of completeness the lengths of the rank 7 trivectors are also included. That $N(C, 7,4)=4$ (and not 5) is shown in [7].

Let $U$ be a fixed 8-dimensional vector space over the complex numbex field and $\Lambda^{3} U$ the space of trivectors considered. If $X \in \Lambda^{3} U$ then $[X]$ denotes the intersection of all subspaces $W$ of $U$ for which $X \in \Lambda^{3} W$. Then $\operatorname{dim}[X]$ is the rank of $X$. The letters $a, b, c, q, r$, $s, p, t$ appearing in the Gurevich classification may be assumed to be independent vectors in $U$. Note that in [2] the " $A$ " has been suppressed.

The equivalence classes are as follows.

$$
\begin{array}{ll}
\text { I: } & 0 \\
\text { II: } & {[a b c]} \\
\text { III: } & {[a q p]+[b r p]} \\
\text { IV: } & {[a q r]+[b r p]+[c p q]} \\
\text { V: } & {[a b c]+[p q r]} \\
\text { VI: } & {[a q p]+[b r p]+[c s p]} \\
\text { VII: } & {[q r s]+[a q p]+[b r p]+[c s p]} \\
\text { VIII: } & {[a b c]+[q r s]+[a q p]}
\end{array}
$$




$$
\begin{array}{ll}
\text { IX: } & {[a b c]+[q r s]+[a q p]+[b r p]} \\
\text { X: } & {[a b c]+[q r s]+[a q p]+[b r p]+[c s p]} \\
\text { XI: } & {[b r p]+[c s p]+[a q p]+[c r t]} \\
\text { XII: } & {[q r s]+[b r p]+[c s p]+[a q p]+[c r t]} \\
\text { XIII: } & {[a b c]+[q r s]+[a q p]+[c r t]} \\
\text { XIV: } & {[a b c]+[q r s]+[a q p]+[b r p]+[c r t]} \\
\text { XV: } & {[a b c]+[q r s]+[a q p]+[b r p]+[c s p]+[c r t]} \\
\text { XIV: } & {[a q p]+[b s t]+[c r t]} \\
\text { XVII: } & {[a q p]+[b r p]+[b s t]+[c r t]} \\
\text { XVIII: } & {[a r s]+[a q p]+[b r p]+[b s t]+[c r t]} \\
\text { XIX: } & {[a q p]+[b r p]+[c s p]+[b s t]+[c r t]} \\
\text { XX: } & {[q r s]+[a q p]+[b r p]+[c s p]+[b s t]+[c r t]} \\
\text { XXI: } & {[a b c]+[a r s]+[a q p]+[b s t]+[c r t]} \\
\text { XXII: } & {[a b c]+[a r s]+[a q p]+[b r p]+[b s t]+[c r t]} \\
\text { XXIII: } & {[a b c]+[a r s]+[a q p]+[b r p]+[c s p]+[b s t]+[c r t]}
\end{array}
$$

Since rank and length remain constant in an equivalence class the terms will be used on the equivalence class itself. There are five equivalence classes of trivectors with rank 7. Three of them, namely VI, VIII, and IX, have length 3 and the other two, VII and $\mathrm{X}$, have length 4 . There are thirteen equivalence classes with rank 8. Two of them, XVI and XIX have length 3; one of them, XV has length 5; and the remaining 10 classes have length 4 . The results are proved as follows.

Consider first a trivector $X$ of rank 7. If it has length 3 then $X=X_{1}+X_{2}+X_{3}$ where each $X_{i}$ is decomposable. If $\left[X_{1}\right] \cap\left[X_{2}\right] \neq 0$ then we may write $X_{1}+X_{2}=x_{1} \wedge\left(x_{2} \wedge x_{3}+x_{4} \wedge x_{5}\right)$ where $x_{1}, \cdots, x_{5}$ are independent vectors in $U$. Then $X_{3}=u \wedge x_{6} \wedge x_{7}$ where $u \in\left\langle x_{1}, \cdots, x_{5}\right\rangle$ and $x_{1}, \cdots, x_{7}$ are independent vectors in $U$. If $u$ is a multiple of $x_{1}$ then $X$ has the form VI where $p=x_{1}$. If $u$ is not a multiple of $x_{1}$ then by rewriting $X_{1}+X_{2}$ we may assume that $u=x_{2}$. (For if $u=\alpha x_{1}+\beta x_{2}+w$ where $\beta \neq 0$ and $w \in\left\langle x_{3}, x_{4}, x_{5}\right\rangle$ then $X_{1}+X_{2}=$ $x_{1} \wedge\left(u \wedge \beta^{-1} x_{3}-\beta^{-1} w \wedge x_{3}+x_{4} \wedge x_{5}\right)$ and $-\beta^{-1} w \wedge x_{3}+x_{4} \wedge x_{5}$ is decomposable.) Then $X$ has the form VIII. If $\left[X_{i}\right] \cap\left[X_{j}\right]=0$ for all pairs $i \neq j$ then we may write $X+X_{2}=x_{1} \wedge x_{2} \wedge x_{3}+x_{4} \wedge x_{5} \wedge x_{6}$ and $X_{3}=u \wedge v \wedge x_{7}$ where $u, v \in\left\langle x_{1}, \cdots, x_{6}\right\rangle$ and $x_{1}, \cdots, x_{7}$ are independent. Then $u=u_{1}+u_{2}, v=v_{1}+v_{2}$ where $u_{1}, v_{1} \in\left[X_{1}\right]$ and $u_{2}, v_{2} \in$ $\left[X_{2}\right]$ so by refactoring $X_{1}$ and $X_{2}$ we may assume that $u=x_{1}+x_{4}$ and $v=x_{2}+x_{5}$. Then $X$ has the form XIX which is equal to $[b(c+p) a]+[q r(x+p)]+[(q-b) p(a+r)]$ where $x_{1}=-b, x_{2}=a, x_{3}=$ $\left.c+p, x_{4}=q, x_{5}=r, x_{6}=s+p, x_{7}=-p\right)$. 
Since all possibilities for rank 7 length 3 trivectors have been considered the remaining classes have length at least 4 . Equivalence class VII then has length 4 and $\mathrm{X}$, which is equal to ([aqp]+ $[(b+s)(r-c) p]+[(a+p) b c]+[(p+q) r s])$ has length 4 also. This takes care of the rank 7 trivectors.

Suppose $X=X_{1}+X_{2}+X_{3}$ is a trivector of length 3 and rank 8, where each $X_{i}$ is decomposable. If $\left[X_{1}\right] \cap\left[X_{2}\right] \neq 0$ then $X_{1}+X_{2}=$ $x_{1} \wedge\left(x_{2} \wedge x_{3}+x_{4} \wedge x_{5}\right)$ and for $X$ to have rank 8 it follows that $\left[X_{3}\right] \cap\left(\left[X_{1}\right]+\left[X_{2}\right]\right)=0$. Therefore $X$ has the form $x_{1} \wedge\left(x_{2} \wedge x_{3}+\right.$ $\left.x_{4} \wedge x_{5}\right)+x_{6} \wedge x_{7} \wedge x_{8}$ or XVI in the Gurevich notation. If $\left[X_{i}\right] \cap$ $\left[X_{j}\right]=0$ for $i \neq j$ then $X_{1}+X_{2}=x_{1} \wedge x_{2} \wedge x_{3}+x_{4} \wedge x_{5} \wedge x_{6}$ and $X_{3}=u \wedge x_{7} \wedge x_{8}$ where $u \in\left\langle x_{1}, \cdots, x_{6}\right\rangle$ and $x_{1}, \cdots, x_{8}$ are independent. By refactoring $X_{1}$ and $X_{2}$ we may assume that $u=x_{1}+x_{4}$ and so $X$ is of type XIX which is equal to $([a q p]+1 / 2[(b+c)(r+s)(p+t)]+$ $1 / 2[(b-c)(r-s)(p-t])$. This takes care of trivectors of rank 8 and length 3. For each of the remaining equivalence classes except $\mathrm{XV}$ we exhibit a length 4 representation.

Types XI, XIII, and XVII are already in the form advertised.

$$
\begin{aligned}
& \mathrm{XII}=[(a-s) q p]+[(q-c)(p+r) s]+[(t+s) c r]+[b r p] . \\
& \mathrm{XIV}=[a b(c-p)]+[(a-r)(b+q) p]+[r q(p-s)]+[c r t] . \\
& \mathrm{XVIII}=[(t-r) b s]+[c r t]+[r(p-s)(b-q)]+[(a-r) q p] . \\
& \mathrm{XX}=[(r+s)(t-r) b]+[(r+s)(r+p)(c-q)]+[(a-r-s) q p] \\
& +[r(b-c)(s-p+t)] \text {. } \\
& \mathrm{XXI}=[(b-r)(c+s) t]+[(a-t) b c]+[a q p]+[r s(q+t)] . \\
& \mathrm{XXII}=[(a+r)(b+2 q)(p-c+1 / 2 s)]+[c r(t-3 b-2 q)] \\
& +[b s(1 / 2 a+3 / 2 r+t)]+[(b+q)(a+2 r)(p-2 c+s)] \text {. } \\
& \mathrm{XXIII}=[(a+1 / 2 s+1 / 2 r) q(b+c+r-s+1 / 2 p+1 / 2 t)] \\
& +[(b+c+1 / 2 q)(r+s)(b+c+1 / 2 p+1 / 2 t)] \\
& +[a(-1 / 2 b+1 / 2 c+q)(-b-c-r+s+1 / 2 p-1 / 2 t)] \\
& +[(b-c)(-1 / 2 a+r-s)(-r+s+1 / 2 p-1 / 2 t)] \text {. }
\end{aligned}
$$

The only item that remains to be justified is that XV has length 5. We write the representative in the form $X=X_{1}+[c r t]$ where $X_{1}=[a b c]+[q r s]+[a q p]+[b r p]+[c s p]$. We note that $X_{1}$ is of type $\mathrm{X}$, has rank 7 , length 4 , from which it follows that $X$ has length at most 5 . We will show that $(t-u) \wedge X$ has length at least 4 for all $u \in\langle a, b, c, q, r, s, p\rangle$. This will complete the proof because if $Y$ is any rank 8 trivector in $\Lambda^{3} U$ with length 4 then at least one of the terms in any representation of $Y$ as a sum of 4 decomposable trivectors must contain a factor of the form $t-u$ for some $u \epsilon$ $\langle a, b, c, q, r, s, p\rangle$, and for this $u$, the length of $(t-u) \wedge Y$ is at most 3 . 
Since $(t-u) \wedge X=t \wedge\left(X_{1}+[u c r]\right)-u \wedge X_{1}$ it is sufficient to prove that $X_{1}+[u c r]$ has length at least 4 for all $u \in\langle a, b, c, q, r$, $s, p\rangle$. Let

$$
u=\alpha_{1} a+\alpha_{2} b+\alpha_{3} c+\alpha_{4} q+\alpha_{5} s+\alpha_{6} r+\alpha_{7} p .
$$

After the substitution

$$
\begin{aligned}
& s \longrightarrow s-\alpha_{7} r+\alpha_{4} c \\
& b \longrightarrow b+\alpha_{1} r
\end{aligned}
$$

with the other letters remaining unchanged we obtain

$$
X_{1}+\left[\operatorname{cr}\left(\alpha_{2} b+\alpha_{5} s\right)\right] \text {. }
$$

If $\alpha_{2}=\alpha_{5}=0$ we have $X_{1}$ which has length 4 . If $\alpha_{2} \neq 0$ then $X_{1}+$ $\left[c r\left(\alpha_{2} b+\alpha_{5} s\right)\right]=\left[\left(\alpha+\alpha_{2} r\right) b\left(c-\alpha_{2}^{-1} p\right)\right]+\left[\left(q+\alpha_{5} c\right) r s\right]+\left[a\left(q+\alpha_{2}^{-1} b\right) p\right]+$ $[c s p] \sim X_{1}$ under the substitution

$$
\begin{aligned}
& a \longrightarrow \alpha_{2}^{-1 / 2}(a-r) \\
& b \longrightarrow \alpha_{2}^{3 / 2} b+\alpha_{5}(c-p) \\
& c \longrightarrow \alpha_{2}^{-1} c \\
& q \longrightarrow \alpha_{2}^{1 / 2} q-\alpha_{2}^{-1} \alpha_{5} c \\
& s \longrightarrow \alpha_{2}(s-p) \\
& r \longrightarrow \alpha_{2}^{-3 / 2} r \\
& p \longrightarrow p .
\end{aligned}
$$

If $\alpha_{2}=0$ and $\alpha_{5} \neq 0$ then

$$
\begin{aligned}
X_{1}+\alpha_{2}[c r s]= & {[a b c]+[b r p]+\left[s\left(q+\alpha_{5} c\right)\left(r-\alpha_{5}^{-1} p\right)\right] } \\
& +\left[\left(a+\alpha_{5}^{-1} s\right) q p\right] \sim X_{1}
\end{aligned}
$$

under the substitution

$$
\begin{aligned}
& a \longrightarrow-\alpha_{5} a \\
& b \longrightarrow-\alpha_{5}(b+p) \\
& c \longrightarrow \alpha_{5}^{-2} c \\
& q \longrightarrow-\alpha_{5}^{-1}(q+c) \\
& r \longrightarrow-\alpha_{5}^{-1} r \\
& s \longrightarrow \alpha_{5}^{2} s \\
& p \longrightarrow p
\end{aligned}
$$

Lastly, we point out also that $N(C, 9,3) \leqq 9$. This follows from (2.5) of [1] since $N(C, 8,3)=5$. The bound 9 is not likely to be the best one however. 


\section{REFERENCES}

1. H. Busemann and D. E. Glassco, Irreducible Sums of Simple Multivectors, Pacific J. Math., 49 (1973), 13-32.

2. G. B. Gurevich, Foundations of the Theory of Algebraic Invariants, P. Noordhoff Ltd., Groningen the Netherlands, (1964).

3. — Sur Les Trivecteurs Dans L'Espace a Sept Dimensions, C. R. Acad. Sc. URSS., 3 (1934), 564-569.

4. - Classification Das Trivecteurs Ayant Le Rang Hui, C. R. Acad. Sc. USSR., 2 (1935), 353-356.

5. — L'Algebre du Trivecteur, Abh. Sem. Vektor u. Lensor. Moscow II, (1935), $51-113$.

6. J. A. Schouten, Tensor Analysis for Physicists, 2nd Edition, Oxford, (1954).

7. - Klassifizierung Der Alternierenden Groszen Dritten Grades in 7 Dimensionen, Circolo. Mat. di. Palermo. Rend., 55 (1931), 137-156.

8. R. Westwick, Trivectors in a space of Seven Dimensions, Canad. Math. Bull., 20 (1977), 401.

Received March 9, 1977 and in revised form April 6, 1978.

UNIVERSity OF BRITISH COLUMBiA

VANCOUVER, B. C. 



\section{PACIFIC JOURNAL OF MATHEMATICS}

\section{EDITORS}

RICHARD ARENS (Managing Editor)

University of California

Los Angeles, CA 90024

Charles W. Curtis

University of Oregon

Eugene, OR 97403

C. C. MOORE

University of California

Berkeley, CA 94720
J. DUGUNDJI

Department of Mathematics

University of Southern California

Los Angeles, CA 90007

R. FINN and J. MILGRAM

Stanford University

Stanford, CA 94305

\section{ASSOCIATE EDITORS}

\section{E. F. BeCKENBACH}

B. H. NeumanN

F. WOLF

K. YoSHIDA

\section{SUPPORTING INSTITUTIONS}

\author{
UNIVERSITY OF SOUTHERN CALIFORNIA \\ STANFORD UNIVERSITY \\ UNIVERSITY OF HAWAII \\ UNIVERSITY OF TOKYO \\ UNIVERSITY OF UTAH \\ WASHINGTON STATE UNIVERSITY \\ UNIVERSITY OF WASHINGTON
}

The Supporting Institutions listed above contribute to the cost of publication of this Journal, but they are not owners or publishers and have no responsibility for its content or policies.

Mathematical papers intended for publication in the Pacific Journal of Mathematics should be in typed form or offset-reproduced, (not dittoed), double spaced with large margins. Please do not use built up fractions in the text of the manuscript. However, you may use them in the displayed equations. Underline Greek letters in red, German in green, and script in blue. The first paragraph or two must be capable of being used separately as a synopsis of the entire paper. Items of the bibliography should not be cited there unless absolutely necessary, in which case they must be identified by author and journal, rather than by item number. Manuscripts, in triplicate, may be sent to any one of the editors. Please classify according to the scheme of Math. Reviews, Index to Vol. 39. All other communications should be addressed to the managing editor, or Elaine Barth, University of California, Los Angeles, California, 90024.

50 reprints to each author are provided free for each article, only if page charges have been substantially paid. Additional copies may be obtained at cost in multiples of 50 .

The Pacific Journal of Mathematics is issued monthly as of January 1966. Regular subscription rate: $\$ 72.00$ a year (6 Vols., 12 issues). Special rate: $\$ 36.00$ a year to individual members of supporting institutions.

Subscriptions, orders for numbers issued in the last three calendar years, and changes of address should be sent to Pacific Journal of Mathematics, P.O. Box 969, Carmel Valley, CA 93924, U.S.A. Older back numbers obtainable from Kraus Periodicals Co., Route 100, Millwood, NY 10546.

PUBLISHED BY PACIFIC JOURNAL OF MATHEMATICS, A NON-PROFIT CORPORATION

Printed at Kokusai Bunken Insatsusha (International Academic Printing Co., Ltd.). 8-8, 3-chome, Takadanobaba, Shinjuku-ku, Tokyo 160, Japan. 


\section{Pacific Journal of Mathematics}

\section{Vol. 80, No. $2 \quad$ October, 1979}

K. Adachi, On the multiplicative Cousin problems for $N^{p}(D) \ldots \ldots \ldots \ldots 297$

Howard Banilower, Isomorphisms and simultaneous extensions in $C(S) \ldots 305$

B. R. Bhonsle and R. A. Prabhu, An inversion formula for a distributional

finite-Hankel-Laplace transformation ................... 313

Douglas S. Bridges, Connectivity properties of metric spaces.......... 325

John Patton Burgess, A selection theorem for group actions ........... 333

Carl Claudius Cowen, Commutants and the operator equations

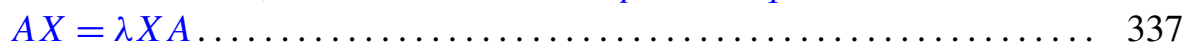

Thomas Curtis Craven, Characterizing reduced Witt rings. II .......... 341

J. Csima, Embedding partial idempotent d-ary quasigroups ............ 351

Sheldon Davis, A cushioning-type weak covering property ............ 359

Micheal Neal Dyer, Nonminimal roots in homotopy trees ............. 371

John Erik Fornaess, Plurisubharmonic defining functions ........... 381

John Fuelberth and James J. Kuzmanovich, On the structure of finitely

generated splitting rings .......................... 389

Irving Leonard Glicksberg, Boundary continuity of some holomorphic

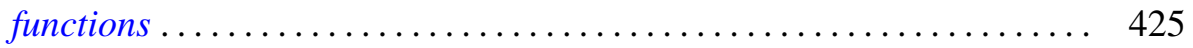

Frank Harary and Robert William Robinson, Generalized Ramsey theory.

IX. Isomorphic factorizations. IV. Isomorphic Ramsey numbers .......

Frank Harary and Allen John Carl Schwenk, The spectral approach to determining the number of walks in a graph...........

David Kent Harrison, Double coset and orbit spaces ..... . .

Shiro Ishikawa, Common fixed points and iteration of commuting

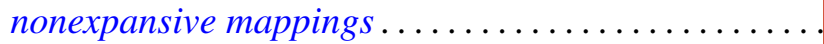

Philip G. Laird, On characterizations of exponential polynomials ........ 503

Y. C. Lee, A Witt's theorem for unimodular lattices ...........

Teck Cheong Lim, On common fixed point sets of commutative

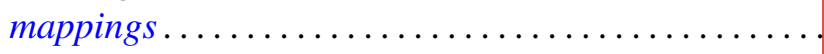

R. S. Pathak, On the Meijer transform of generalized functions ...

T. S. Ravisankar and U. S. Shukla, Structure of $\Gamma$-rings . . .

Olaf von Grudzinski, Examples of solvable and nonsolvable convolution

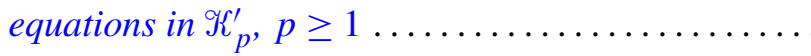

